\title{
STUDY ON INFLUENCE OF POSITIONS OF CORE WALL FOR STRUCTURES WITH SET AND STEP BACK CONFIGURATION
}

\author{
Vijayalakshmi Patel.K $\mathbf{K}^{\mathbf{1}}$, Manjunatha.L ${ }^{2}$ \\ ${ }^{1}$ M.Tech.Student, Structural Engineering, Department Of Civil Engineering, SJB Institute of Technology, Bangalore \\ ${ }^{2}$ Assistant Professor, Structural Engineering, Department Of Civil Engineering,SJB Institute of Technology, \\ Bangalore
}

\begin{abstract}
In recent decades economic expansion and urbanization has brought about development of massive amount of multistoried structures which has imparted lack of plain region for development of buildings.This constitutes requirement for construction on slanted ground. Structures built on slopes have a distinct structural configuration with irregularity in mass and rigidity; hence they are liable to damage amid seismic tremor. It is difficult to prevent earthquakes however; the effect can be reduced by safe design and construction work.

Core walls are most commonly used in multi storied structures for enclosing elevators, staircase or a lift and they should be placed appropriately to access various storey.The behavior of structures with the location of core wall on a flat ground is distinctive from the sloped ground.In contrast with plain ground,sloped ground has varied stiffness along its elevation which causes change in the focus of mass and stiffness.Improper positioning of lift core in sloped structure canlead to excessive deformations and torsion.Hence in the present study, an attempt is made in studying the consequences on location of core walls on a level ground and sloped ground. A steel building model with $G+20$ stories is considered and a time history type of examining for building with zone $V$ with medium soil condition is carried out in structural engineered software ETABS. Finally the ideal position of core wallis determined and the seismic reactions results are examined.
\end{abstract}

Keywords: Buildings on slopes, Shear wall, Torsion, Displacements, etc....

\section{INTRODUCTION}

Rapid urbanization andproliferation in population growth in hilly terrains have brought necessity for development of multi storied buildings. Buildings when developed on these areas commonly have a discrete structural configuration and their behavior is unique when compared to buildings lying on level geography, as it isunsymmetricaland uneven in nature. Due to site conditions structures on hill slope are characterized by varying length of columns which brings about variation in stiffness.

A standard categorization of structures on slopesincludes varying column lengths and lack of proper foundation embedded into the soil. The columns are stiff on hill side and it attracts in massive amount of lateral forces and is liable to damage. The unforeseen variation in mass and rigidity brings about eccentricity in focal point of mass and focal point of stiffness at every storey.

During tremor, these structures develop huge twisting moment. A short column and long column of comparable cross section moves on a level plane with same magnitude. Since short columns are stiffthey pull in huge magnitude of forces and it is not capable of withstanding them they suffer enormous damage leading to failure. This is stated as short column effect.
In India, hilly terrains are found in northern parts and from the impacts seen from the late Sikkim tremor the significance of structures on uneven ground were perceived. It is seen, amid a tremor structures on sloping ground have experienced high level of destruction prompting collapse; however they have been intended for safety of people in contrast to natural disaster. Hence when constructing the buildings on hilly terrain, awareness should be kept for making these buildings seismic resistant.

Past research works shows a brief overview on investigations conducted on sloped building. Birajdar et al (2004)[4] studied buildings with setback configurations, step back configuration and combination of the two. All the building configurations were evaluated adopting response spectrum and torsional impacts were included. It is witnessed as; step back structures are feasible to seismic destruction in contrast with other building configurations. Study on structures lying on different sloping angles was also assessed from the review seen from various works. Manish D Meshram et al (2016) [9] conductedanalysis on structures located on hill slopes with 18,11 \& 27 degreeusing response spectrum method. It was seen that, bending moments \& shearing action is more in sloped building than plain building. Higher values of sloping angles develop larger base shear than smaller sloping angles. Variation in the total story height of building also disturbs the performance of structure on sloped ground.Birajdar et 
al (2004)[4]varied thetotal height from four to eleven inferring that higher the tallness of building more will be the natural period \& displacements. Core walls are usually implemented in structures for lift cores. When these core walls are positioned at improper locations they impart unwanted torsional impact on buildings. Rupali Gaud et al (2016)[5] investigated the appropriate position of lift core at different places and the functioning of structures for different zones of seismic regions with an unsymmetrical plan modelled through STAAD PRO. Lift cores are positioned at the centre and around the edges and its performance during a tremor is studied by equivalent static method. From the outcome of analysis it was inferred that presence of the lift core enhances the structures resistance to seismic forces and also lift core at centre are desirable than edges.

\section{AIM OF STUDY}

- To study the seismic action of steel structure with set \& step back configuration

- To examine the outcome for set \& step back building with various positions of core walls.

- To determine the ideal position for core wall for the considered steel structure byassessingvarious seismicparameters of the investigation such as displacements, twisting moments etc.

\section{BUILDING MODELS}

In the present study, set \& step back steel structural configuration isdeveloped and examined using a time history method with bhuj earthquake by means of ETABS software. In set \& step back building, setbacks at $10^{\text {th }} \&$ $15^{\text {th }}$ storey are applied as shown in figure 3.2 along $\mathrm{x}$ and $\mathrm{y}$ direction of the plan view, also the building is sloped for an angle of 30.9 degree with soil condition as medium and zone factor $\mathrm{V}$.

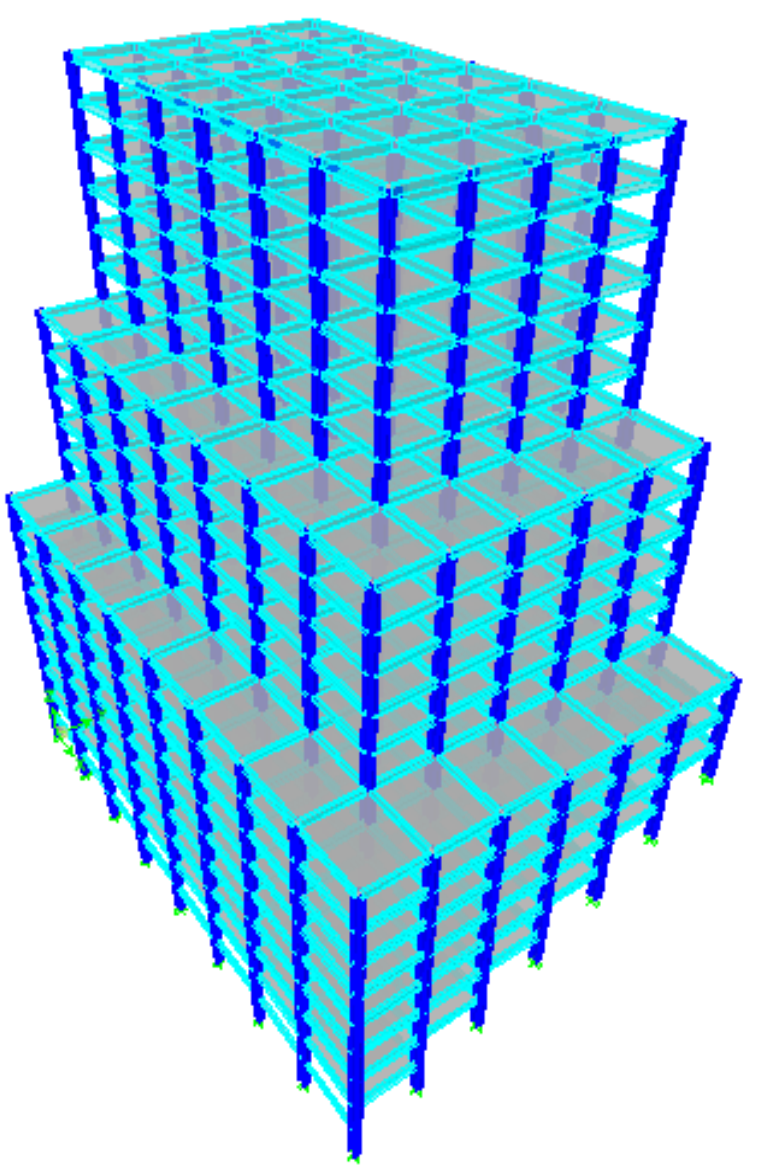

Fig 3.1: 3D view of set \& step back structure

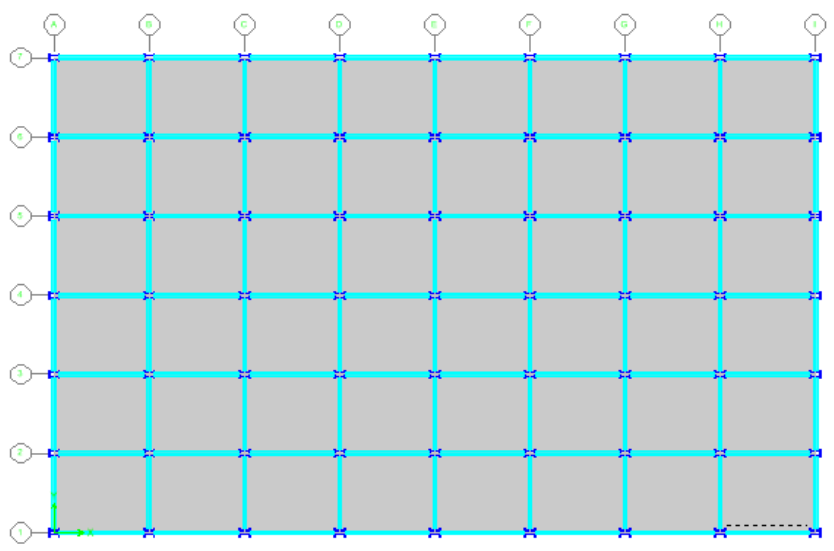

Fig 3.2: Plan view of steel building 


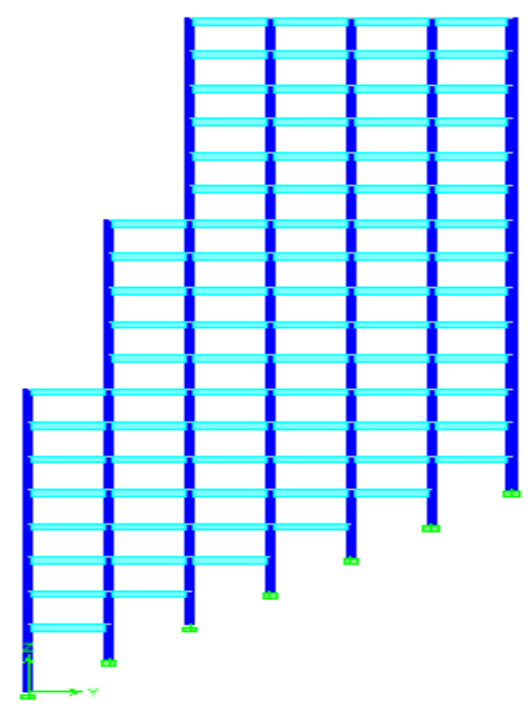

Fig 3.3: Set \& step back building with elevation view

In understanding the performance of the building at different positions of core walls amid a sesmic action, in the study 9 positions are choosen. Core walls are placed in the form of $\mathrm{C} \& \mathrm{U}$ shaped walls as shown below

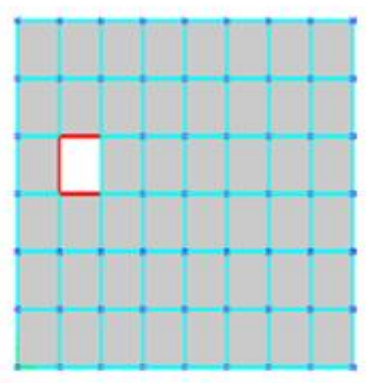

SW1C

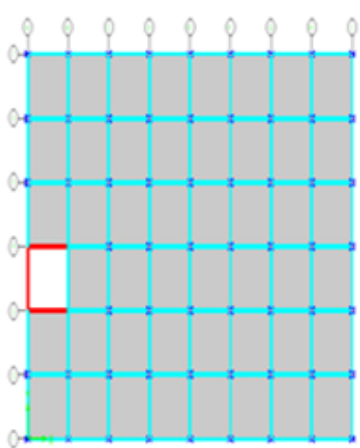

SW3C

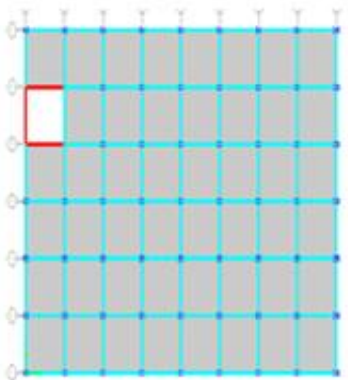

SW2C

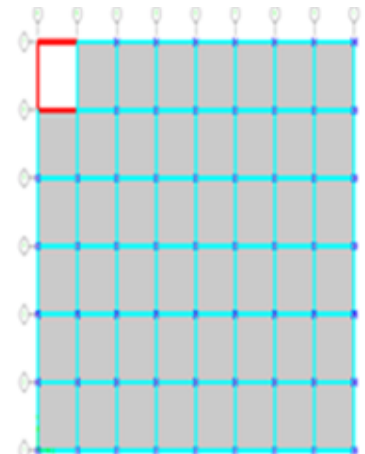

SW4C

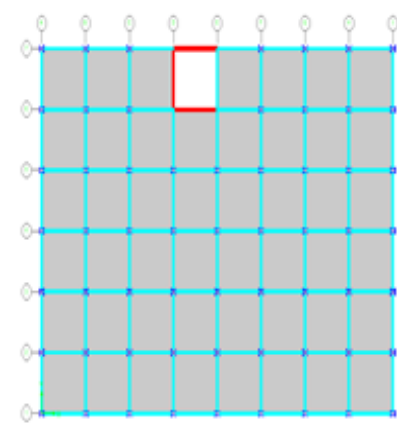

SW5C

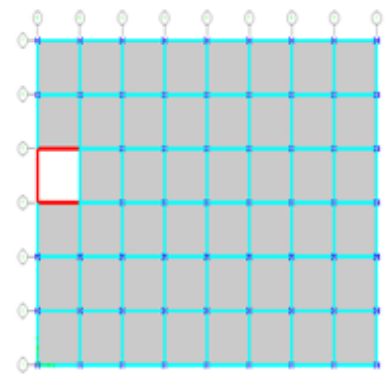

SW7C

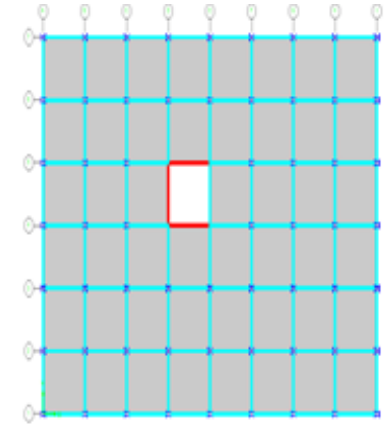

SW6C

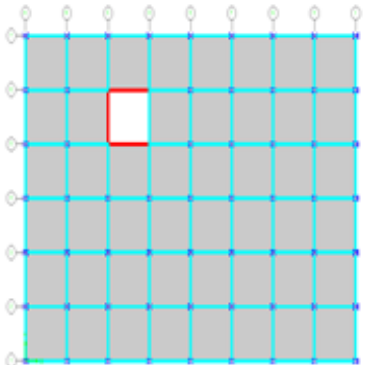

SW8C

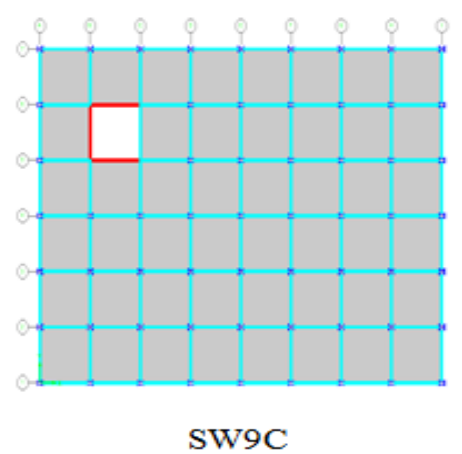

Fig 3.3 Positions of $\mathrm{C}$ shaped core walls

$\mathrm{U}$ shaped core walls are situated at same 9 places as of the $\mathrm{C}$ shaped core walls and model is reviewed. Therefore overall 19 building models are developed including the bare model (without core wall). Among these a suitable location of core wall for a steel set \& step back configuration are examined. 


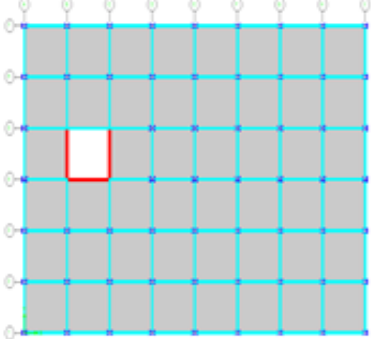

SW1U

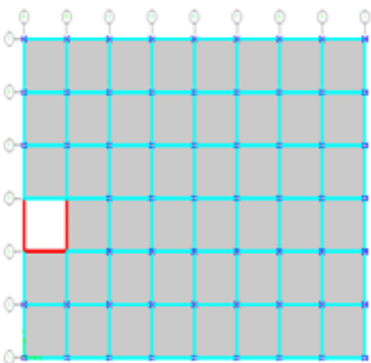

SW3U

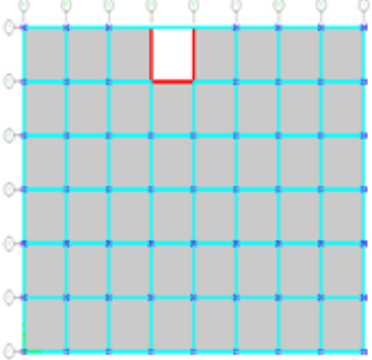

SW5U

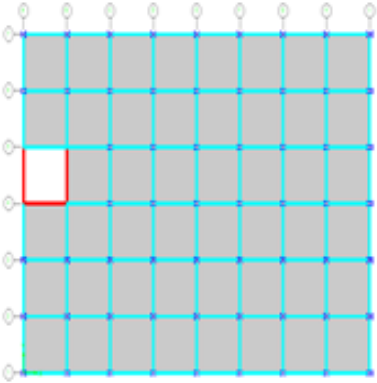

SW7U

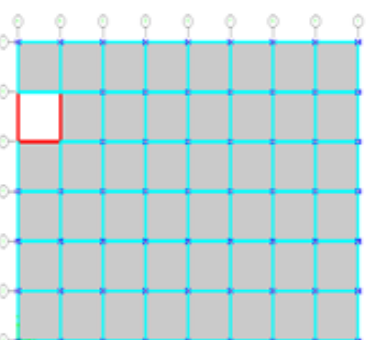

SW2U

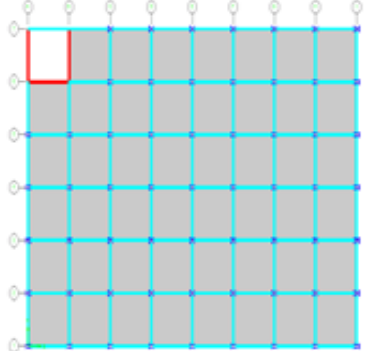

SW4U

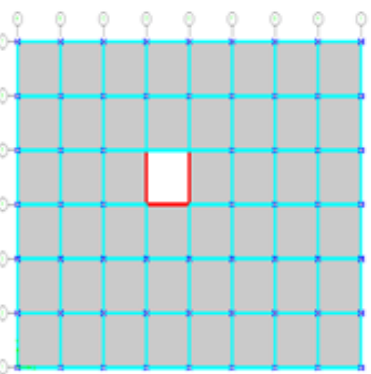

SW6U

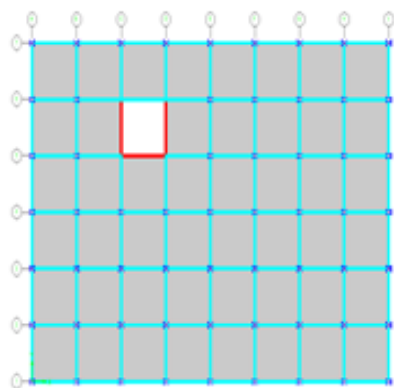

SW8U

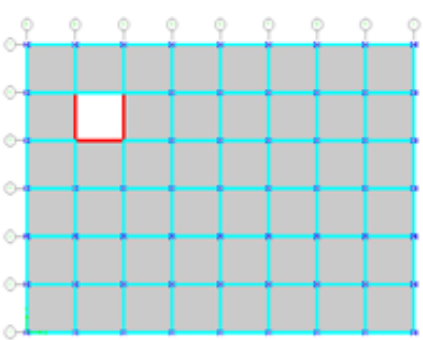

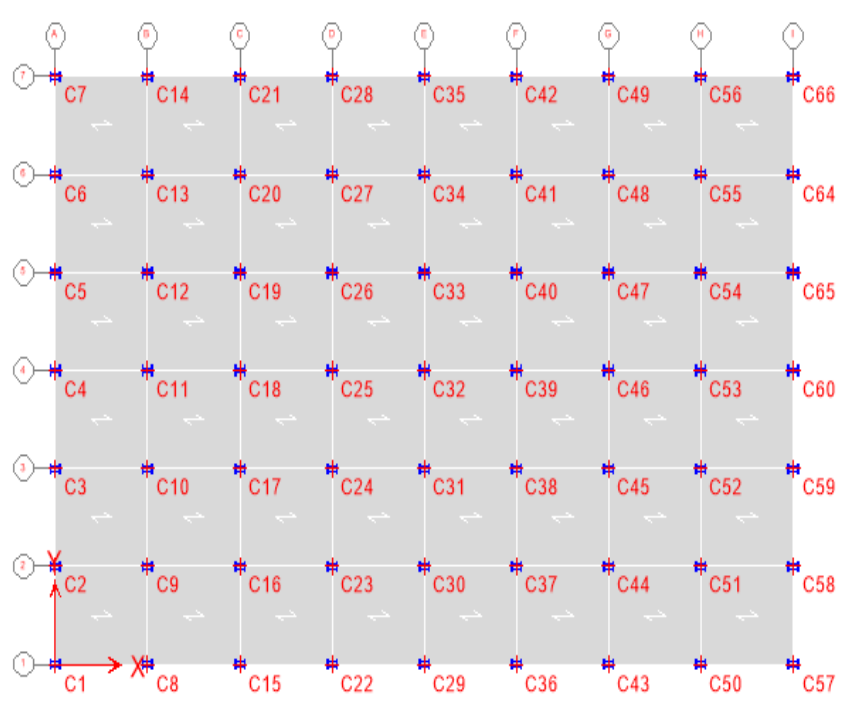

Fig 3.5: Representing the column numbering

\subsection{Building Model Description}

\begin{tabular}{|l|l|}
\hline Plan size & $48 \mathrm{~m} \times 30 \mathrm{~m}$ \\
\hline Building height & $60 \mathrm{~m}$ \\
\hline Storey height & $3 \mathrm{~m}$ \\
\hline Grade of structural steel & Fe340 \\
\hline Grade of concrete & M30 \\
\hline Beam & ISMB 600 \\
\hline Column & Built-up \\
\hline Deck slab & $200 \mathrm{~mm}$ \\
\hline Shear wall & $300 \mathrm{~mm}$ \\
\hline Seismic zone & V \\
\hline Soil condition & Medium \\
\hline Live load & $4 \mathrm{kN} / \mathrm{m}^{2}$ \\
\hline Importance factor & 1 \\
\hline Response reduction factor & 5 \\
\hline
\end{tabular}

\section{RESULTS}

In the study, chiefly the torsional behavior and maximum displacements are studied for various positions of core wall in set \& step back building.Listed tables and graphs are exhibited to find proficientcore wall location

\subsection{Maximum Torsion}

From graph 4.1, for various positions of core wall for a set \& step back configuration, it is observed that building without core wall has a torsional value of $7.35 \mathrm{kN}-\mathrm{m} \&$ $1.53 \mathrm{kN}-\mathrm{m}$ for seismic load in $\mathrm{x}$ and $\mathrm{y}$ direction. Among various positions sw7u has about $91.6 \%$ \& $61.3 \%$ lesser twisting moments induced in columns for seismicloads in $\mathrm{x}$ $\&$ y direction when related with bare model. Hence sw $7 \mathrm{u}$ is preferred as an accurate position for core wall with the torsional effects being minimized.

SW9U

Fig 3.4: Positions of $\mathrm{C}$ shaped core walls 
Table 4.1: Maximum torsion for various positions of core wall

\begin{tabular}{|l|l|l|l|}
\hline $\begin{array}{l}\text { SL } \\
\text { NO }\end{array}$ & POSITION & $\begin{array}{l}\text { MAX } \\
\text { TORSION } \\
\text { THX kN-m }\end{array}$ & $\begin{array}{l}\text { MAX } \\
\text { TORSION } \\
\text { THY kN-m }\end{array}$ \\
\hline 1 & bare & 7.359 & 1.583 \\
\hline 2 & sw1c & 2.267 & 2.396 \\
\hline 3 & sw1u & 13.5 & 6.173 \\
\hline 4 & sw2c & 1.996 & 8.956 \\
\hline 5 & sw2u & 2.327 & 4.642 \\
\hline 6 & sw3c & 3.321 & 2.095 \\
\hline 7 & sw3u & 5.388 & 2.231 \\
\hline 8 & sw4c & 5.266 & 9.94 \\
\hline 9 & sw4u & 4.45 & 13.48 \\
\hline 10 & sw5c & 4.106 & 6.412 \\
\hline 11 & sw5u & 8.686 & 7.816 \\
\hline 12 & sw6c & 8.652 & 9.02 \\
\hline 13 & sw6u & 4.11 & 11.612 \\
\hline 14 & sw7c & 2.241 & 3.154 \\
\hline 15 & sw7u & 0.614 & 0.612 \\
\hline 16 & sw8c & 8.106 & 5.838 \\
\hline 17 & sw8u & 4.992 & 5.272 \\
\hline 18 & Sw9c & 1.399 & 5.891 \\
\hline 19 & sw9u & 11.26 & 8.5 \\
\hline & & & \\
\hline
\end{tabular}

\section{Variation of torsion in set \& step back building}

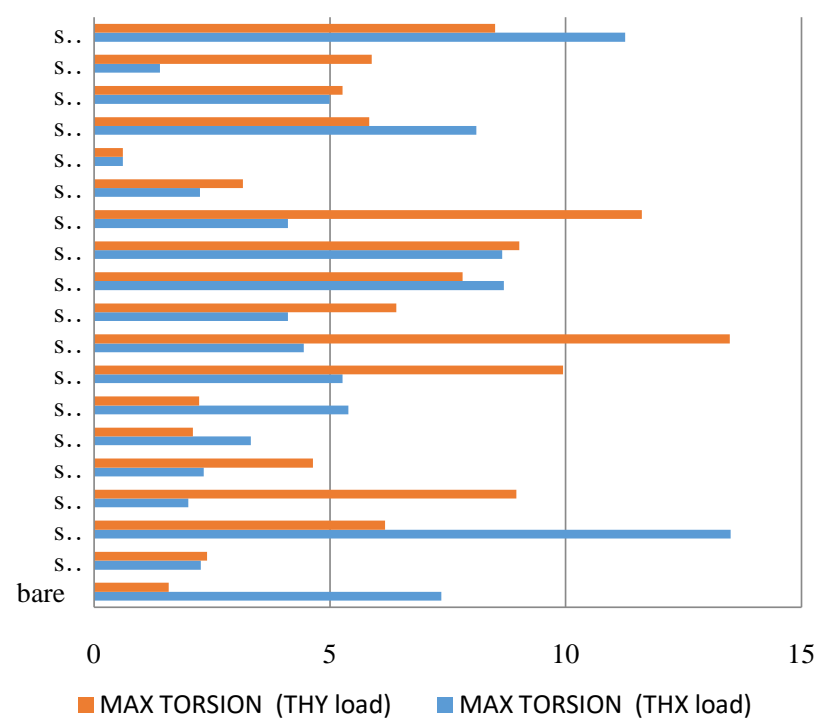

Fig 4.1: Maximum torsion in set \& step back structures

\subsection{Maximum Displacements}

To check if the building displacements are within thecodal norms, a criteria which governs the maximum displacements as mentioned in IS 1893-2002.Accordingly the maximum displacement in a building should be $\mathrm{H} / 500$ where $\mathrm{H}$ is the overall height of the structure.In the study the total height is $60 \mathrm{~m}$, hence $60 / 500=0.12 \mathrm{~m}$. Therefore maximum displacements in set \& step back building should be within $120 \mathrm{~mm}$.

From graph 4.2, it is noticed that amongst $\mathrm{C}$ shaped core wall positions sw1c, sw2c, sw9c \& sw7c have smaller displacements than bare models and similarly among the $\mathrm{U}$ shaped core walls it is seen sw7u has least storey displacements. Meanwhile sw7u has approximately $83.07 \%$ \& $72.49 \%$ lesser displacements in $\mathrm{x} \& \mathrm{y}$ direction which has the utmost value of reduction of displacement among various positions of core wall. Hence sw $7 \mathrm{u}$ is found desirable.

Table 4.2: Maximum displacements for various positions of

\begin{tabular}{|c|c|c|c|}
\hline $\begin{array}{l}\text { SL } \\
\text { NO }\end{array}$ & POSITION & $\begin{array}{l}\text { MAX } \\
\mathbf{m}\end{array}$ & $\begin{array}{ll}\text { MAX } & \text { UY } \\
\text { m } & \end{array}$ \\
\hline 1 & bare & 0.026 & 0.0207 \\
\hline 2 & sw1c & 0.0168 & 0.0118 \\
\hline 3 & sw1u & 0.0446 & 0.041 \\
\hline 4 & sw2c & 0.0149 & 0.0196 \\
\hline 5 & sw2u & 0.0111 & 0.0136 \\
\hline 6 & sw3c & 0.031 & 0.0099 \\
\hline 7 & sw3u & 0.0372 & 0.0077 \\
\hline 8 & sw4c & 0.009 & 0.0228 \\
\hline 9 & sw4u & 0.0036 & 0.0313 \\
\hline 10 & sw5c & 0.0057 & 0.0335 \\
\hline 11 & sw5u & 0.0127 & 0.0572 \\
\hline 12 & sw6c & 0.0528 & 0.0643 \\
\hline 13 & sw6u & 0.0245 & 0.9952 \\
\hline 14 & sw7c & 0.021 & 0.012 \\
\hline 15 & sw7u & 0.0044 & 0.0023 \\
\hline 16 & sw8c & 0.0323 & 0.0225 \\
\hline 17 & sw8u & 0.0127 & 0.051 \\
\hline 18 & Sw9c & 0.0077 & 0.0144 \\
\hline 19 & sw9u & 0.0088 & 0.0243 \\
\hline
\end{tabular}




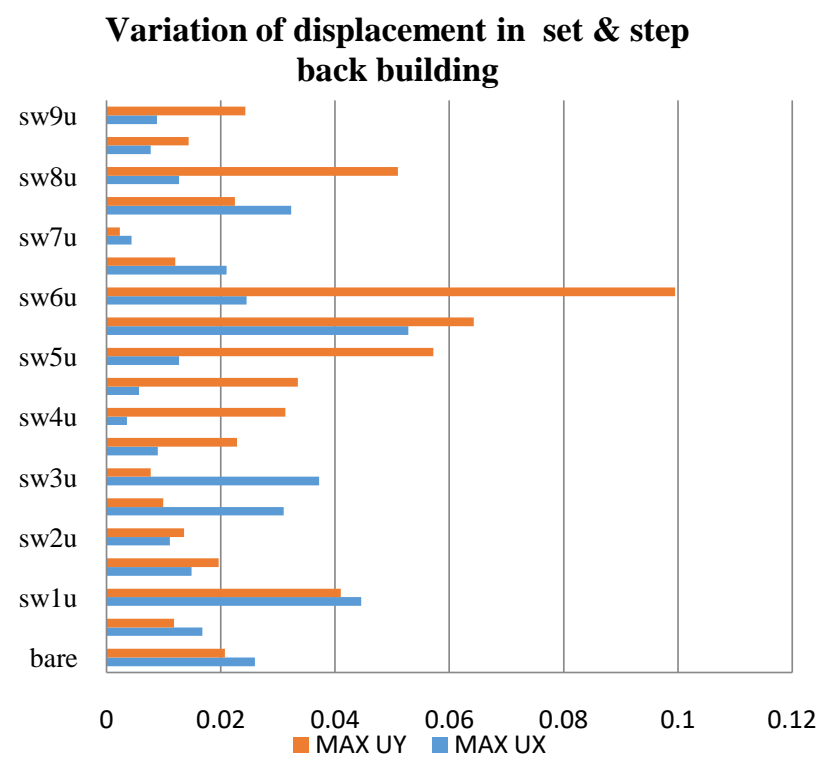

Fig 4.2: Maximum displacements along $x$ \& y direction for set \& step back building

Perceiving the maximum values of torsion and displacements for $\mathrm{C} \& \mathrm{U}$ shaped core wall positions, outcomes exhibit that sw7u has beenestablished as an appropriate location for set \& step back structures. Along with it sw7c,sw5u,sw6c and sw9u are few critical positions considered for brief analysis

Henceforth a detail examination is prepared for these five locations mainly sw7u, sw6c, sw9u, sw7c \& sw5u.

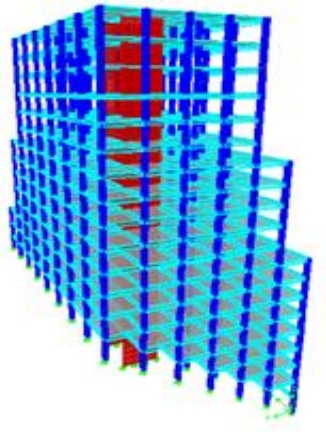

SW9U

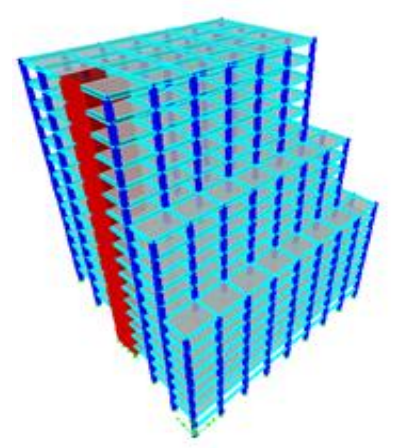

SW7C

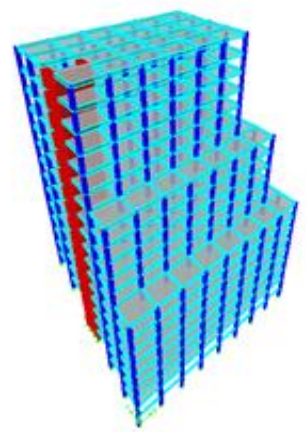

SW7U

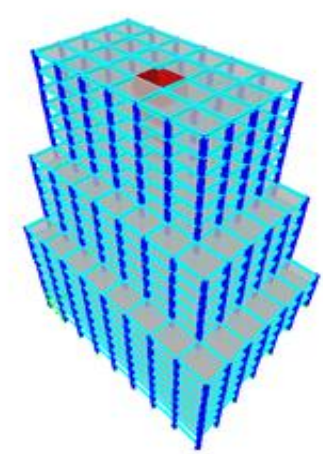

SW6C

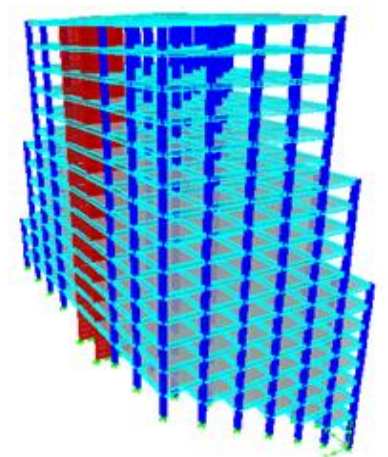

SW5U

\subsection{Brief Study on Core Wall Positions}

\subsubsection{Natural Time Period for Set \& Step Back} Structures

Observing fig 4.3, structure without core walls had greater natural period indicating higher vibration and lesser stiffness of the structure. In the occurrence of various positions of core walls, the natural time period has condensed. Decline in time period is about $12.8 \%-16.9 \%$ when related to bare model.

\section{Time period variation}

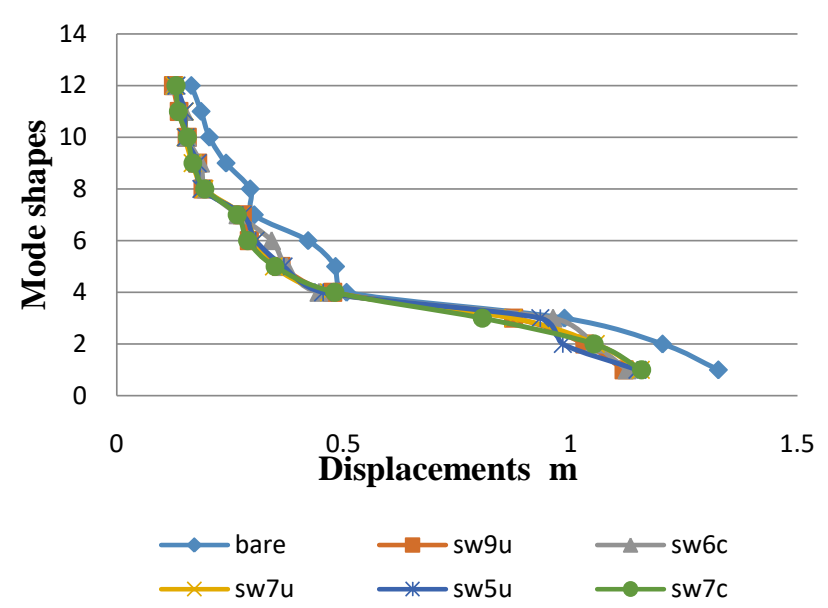

Fig 4.3: Time period for set \& step back structures.

\subsubsection{Displacements at Different Storeys}

From graph 4.4 and 4.5 , observing the graph it is seen all core wall positions have displacements within $120 \mathrm{~mm}$ and maximum displacement are obtained at top storey. Sw7u has lesser values of displacement compared to remaining positions which is roughly $83.82 \% \& 89.09 \%$ along $\mathrm{x} \& \mathrm{y}$ direction when related with bare model values. 


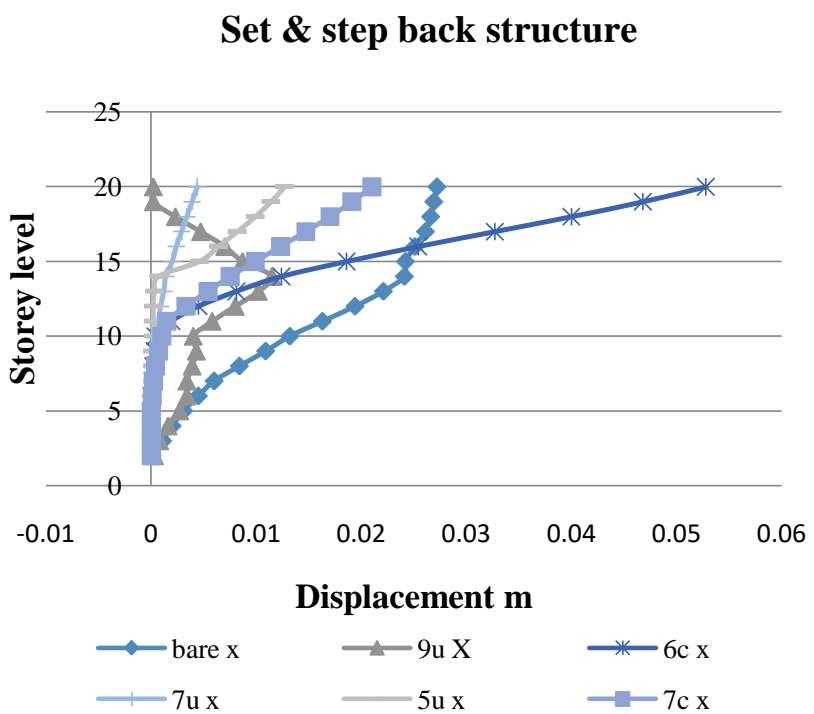

Fig 4.4: Displacements along $x$ direction for set \& step back building

\section{Set \& step back structure}

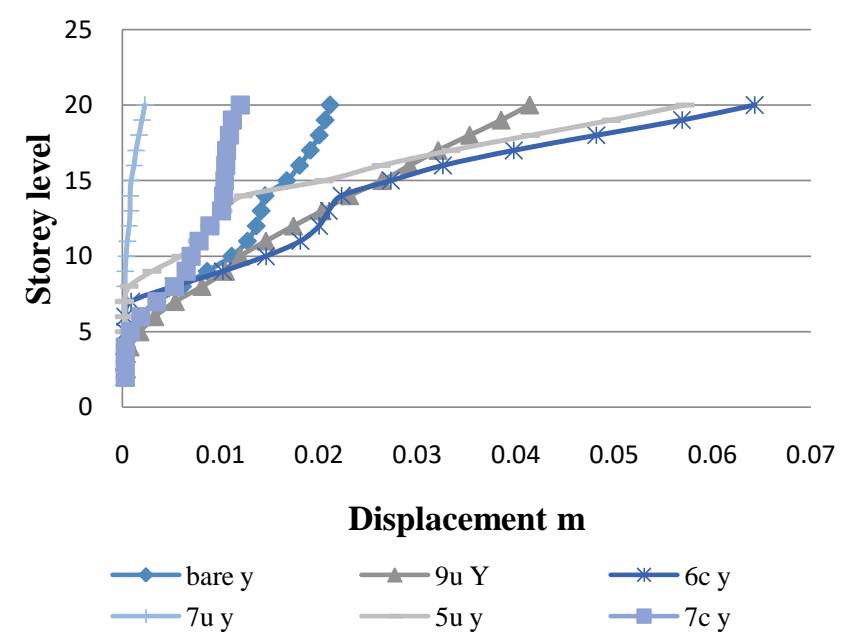

Fig 4.5: Displacements along y direction for step back building

\subsubsection{Variation of Torsion in Set \& Step Back}

\section{Structures}

It is observed that bare model has maximum torsional value at $7^{\text {th }}$ storey for column c7 and column c66 with $7.35 \mathrm{kN}-\mathrm{m}$ and $1.583 \mathrm{kN}-\mathrm{m}$ along $\mathrm{x} \& \mathrm{y}$ direction respectively. It is seen from graph that the torsional values increases up to a maximum value and decreases suddenly. Maximum torsion values are found near the hill side of the sloping ground for various positions of core wall. Among $\mathrm{C} \& \mathrm{U}$ shaped core walls $91 \%$ and $61.23 \%$ torsion are found for sw7u in contrast with bare model.In sw $7 \mathrm{u}$ position, maximum torsion is experienced by column c49 at storey 20 .

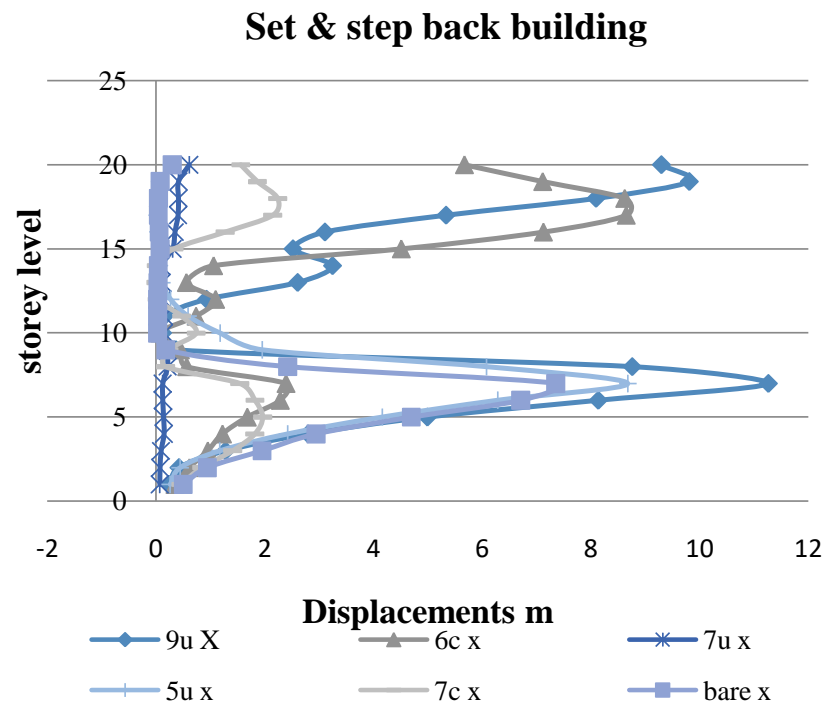

Fig 4.6: Torsional reactions in columns at different storey for seismic load in $\mathrm{x}$ direction

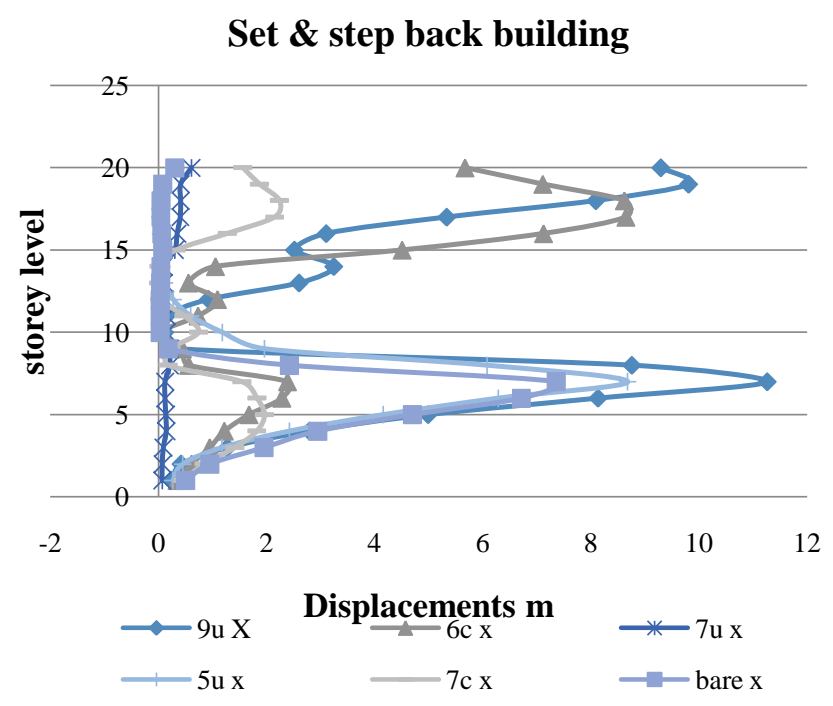

Fig 4.7: Torsional reaction in columns at different storey for seismic load in y direction

\section{CONCLUSION}

a. A set \& step back building comprises ofvariable column lengths along the slope, the columns situated on higher end of slope has greater tendency to undergo torsion.

b. Reviewing time period examination of various models, it is marked that including core walls in structures reduces the natural time period of structures in turn increasing the strength of building to take up higher input frequencies of earthquake making the structures stiffer. In presence of core walls, structures have showed a reduced time period by $12.84 \%-16.9 \%$.

c. From displacement graphs sw7u yields $83 \%$ \& $89.1 \%$ smaller values for $\mathrm{x} \& \mathrm{y}$ direction w.r.t bare models. Therefore $\mathrm{sw} 7 \mathrm{u}$ is considered a reliable position. 
d. From torsion graphs maximum torsion is developed in columns on higher side of slopes, for bare model its felt by $\mathrm{c} 7$ and $\mathrm{c} 66$ at $7^{\text {th }}$ storey for seismic load in $\mathrm{x} \& \mathrm{y}$ direction. Among the provided shapes and locations lesser torsion is developed in $\operatorname{sw} 7 \mathrm{u}$ at $20^{\text {th }}$ storey by column c49.Hence while examining the model for torsion aspect sw7u is seen to be appropriate.

e. Finally it is concluded that the ideal location for core walls is sw $7 \mathrm{u}$ for set \& step back buildings reducing the displacements and also torsional moments.

\section{REFERENCES}

[1]. SandipDoijad, SurekhaBhalachandra, "Seismic Behavior of RC Buildings Constricted on Plain and Sloping Ground with Different Configuration of Shear Walls", Journal of Civil Engineering and Environmental Technology, Volume 2,Number 10,April-June ,2015 pp.5965

[2]. Dr.S.H.Mahure and Amit S.Chavhan, "Vertical Irregularities in RC Building Controlled By Finding Exact Position of Shear Wall", International Journal of Innovative Research in Science Engineering and Technology, Volume 4, Issue 7,July 2015.

[3]. Kiran.T, N.Jayaramappa "Seismic Performance of RC Frame Buildings Resting on Sloping Ground",Volume 14,Issue 2,April 2017,pp 67-74

[4]. Birajdar B. G,Nalawade .S.S "Seismic Analysis Of Buildings Resting On Sloping Ground", $13^{\text {th }}$ World Conference on Earthquake Engineering, Vancouver, B.C, Canada, August 1-6,2004,Paper No.1472

[5]. Rupali Goud and SumitPahwa , "Study of Effect of Location of Lift Core Shear Wall under earthquake loads", International Journal of Science Technology \& Engineering, Volume 2,Issue 07,January 2016

[6]. Anila Anna, Samson, PreethaPrabhakaran and Dr.Girija $\mathrm{K}$, "Performance of Shear Wall Building during Seismic Excitations" ,International Journal of Civil Engineering and Technology, Volume 5,Issue 12,December(2014)pp.77-83.

[7]. MoulshreeTripathi, Mary Williams $P$ and Dr.R.K.Tripathi "Behavior of Tall Structures with Eccentric Loading", International Journal of Research in Chemical, Metallurgical and Civil Engg. Volume 3, Issue 2, (2016)

[8]. Lakshmi K.O, Prof. Jjayasree Ramanujan, Mrs.Bindu Sunil, Dr.LajuKotaallil, Prof.Mercy Joseph Poweth "Effect of Shear Wall location in Buildings subjected to Seismic Loads", ISOI Journal of Engineering and Computer Science, Volume 1,Issue1,pp.07-17.

[9]. Manish D Meshram,Ashok R Mundhala "Earthquake analysis of RC Buildings on Hilly Terrain",International Journal of Innovative and Emerging Research in Engineering, Volume 3,Special Issue 1,2016. 